\title{
Drawn to Scale: Mapping Operations in Racialized Landscapes
}

\author{
JAMES FORREN
}

Dalhousie University
EMILY WILSON

Dalhousie University

\author{
SIBO QIN \\ Harbin University
}

\begin{abstract}
This paper traces mapping activities for a small museum of African-Nova Scotian heritage. Drawing from James Corner's taxonomy of mapping operations, the project leverages form and composition in mapping practice for design generation in racialized landscapes. This analysis frames an understanding of the capacity of mapping operations to assist agency in civic discourse through its construction of visibility and spatialtemporal connection. This capacity informs the project's mapping activities: projective acts which simultaneously prefigure design interventions for an interpretive landscape while serving as instruments for community discourse, visibility, and engagement.
\end{abstract}

\section{INTRODUCTION}

James Corner's essay, "The Agency of Mapping," describes mapping operations as compositional activities informing the generation of three-dimensional space. ${ }^{1}$ By the conclusion of the chapter he hints at an ethical dimension to this practice, but stops short of spelling out criteria, standards, or methods for applying it socially and politically charged contexts. If we do apply Corner's framework to these contexts what connections can we draw between the tools of spatial composition and the dynamics of social and political geographies? How might situating Corner's knowledge framework in a particular social, political geography yield insights into the broader agency of formal, compositional tools?

This paper situates Corner's framework in racialized North American spatial contexts to discover what the rigorous compositional logic can tell us about broader social, cultural and economic constructions of space. Our hypothesis is that articulating criteria and standards of mapping operations in racialized contexts can provide a platform for better-informed practices in architecture, urban, and landscape design.

The methods presented are analytical and practice-based. First, an analysis of two maps depicting racial constructions of space in the state of Virginia. Second, practice-based research in a specific racialized context: Africville, Nova Scotia. Africville is the landscape formerly occupied by a displaced largely African-Canadian population in Halifax, Nova Scotia. The outcomes introduced include methods of practice which account for authorial bias while engaging in generative design activities in the landscape.
This practice-based work supports visibility efforts by the Africville Museum: stewards for the heritage of Africville. Presented here is the first phase of research, the construction of maps. The maps - surveys of the landscape combining knowledge from technical and humanities research - lays the ground work for the design of an interpretive walk through community engagement (Figure 1$)^{2}$ and constructs templates for a future program of interactive virtual maps.

\section{JAMES CORNER AND MAPPING OPERATIONS}

Maps are instruments of spatial practice utilizing form and composition to organize and depict spatial relationships. In "The Agency of Mapping" Corner defines "mapping operations" by deconstructing the constituent components and their inter-relationships. ${ }^{3}$ Corner first deconstructs the elements of mapping into "fields," "extracts," and "plotting." Fields are the neutral landscape of the map; extracts are the 'stuff' or 'things' which occupy the field; and plottings are the networks of relationships between extracts in the field. These ingredients play out in various formations and choreographies: a taxonomy labeled by Corner as drift, layering, gameboard, and rhizome. Drift describes an openly subjective practice, akin to Situationist psychogeographies, wherein disparate sets of data are associated through the lens of the author. Layering delaminates networks, infrastructure, program, and other data into sets of strata: an action which immediately suggests design possibilities and strategies. Gameboard synthesizes drift and layering as the data sets of layering are actively manipulated. And the rhizome coalesces data sets in open networks, the DNA of which gives form to the map based on the nature and magnitude of the data.

These different types of mapping represent for Corner different forms of spatial discourse which both permit and deny varying degrees of spatial awareness and possibility. Towards the chapter's close he touches on the ethical component of this discourse: identifying democratic and operational opportunities within it.

"Given the complex nature of late capitalist culture ... it is becoming ever more difficult for urban designers and planners to play a role in the development of cities and regions .... There is a kind of inertia and leveling of possibilities as it becomes politically impossible in a mass democracy to do anything out of the ordinary. While there is no shortage of theories and ideas for addressing this condition more critically, there has been very little development of new 
operational techniques for actualizing them. In other words, the difficulty today is less a crisis of what to do than of how to do anything at all."

By positioning these "new operational techniques" in racialized contexts this paper describes criteria and standards for how to do anything out of the ordinary in these contexts.

\section{RACIALIZED LANDSCAPES}

Racialized landscapes are social, political, and economic geographies where the construction of race - or difference based on skin color - impacts dynamics of power, privilege, and visibility in the broader social, political, and economic environment. ${ }^{5}$ David Theo Goldberg in Racist Culture outlines a sequence of exchanges - "exclusion," "integration," and "incorporation" - between dominant and insurgent populations in these contexts. Exclusion is the restriction of insurgent population's access to representation, mobility, goods, services and other forms of civic agency; integration is the prescribed access to these resources on the dominant population's terms; and incorporation is a push-pull between dominant and insurgent groups where this agency is negotiated, often against the dominant population's will. Goldberg, in accounts of the modern South African state, observes these dynamics evolving in sequence as exchanges between dominant and insurgent groups modify their capacities and interests. ${ }^{6}$

An example of this cycle has been underway in Halifax, Nova Scotia between residents of European and African heritages around the community of Africville. Africville is located the northern end of the Halifax peninsula and from the late nineteenth century to mid twentieth century the City of Halifax and Africville engaged a cycle of exclusion and integration. Decades of targeted neglect and exclusion by the City of Halifax included the denial of city services like sewage, water, police protection and waste disposal; the refusal of building and repair permits; and the circumscription of the community with an infectious disease hospital, sewer discharge, prison, slaughterhouse, and city dump. Poorly documented lease agreements and transfers of ownership left residents vulnerable to city demands when finally the land was claimed for industrial development and transportation infrastructure. Over several years in the 1960s Africville was rapidly dismantled through state directed integration: networks of families were separated and forcibly relocated to other parts of Halifax and houses and community facilities bulldozed.?

After decades of ongoing advocacy by former residents and their descendants there is evidence that this dynamic has shifted to a phase of incorporation through more recent events like the 2004 United Nations identification of Africville's treatment by the City of Halifax as an example of "contemporary racist urban policy." ${ }^{8}$ In 2010 the mayor of the then Halifax Regional Municipality issued an official apology and the municipality reached a settlement granting land, financing, and infrastructure promises to a trust owned and operated by representatives of the community. ${ }^{9}$ However, the terms of this settlement have yet to be fully met. Heritage neglect continues in a lack of pedestrian or public transportation infrastructure, weak bylaw enforcement protecting use of the land, and a dearth of adequate signage among other municipal short falls..$^{10}$ Presently a class action lawsuit stands before the Nova Scotia Supreme Court demanding reparations for individual families. ${ }^{11}$ These events reveal the marks of a city grudgingly giving recognition to an active, mobilized insurgent population.

In addition to lineage accounts, community gatherings and civic activism the instruments of maps promote acts of incorporation both within and outside the community. Through their synthesis of space and time maps stitch together narratives for a community which is dispersed spatially and temporally. Maps of the original community are reproduced in books published by the Africville Genealogical Society (AGS), a civic organization arising after relocation. The Africville Museum has undertaken creative mapping exercises to perpetuate a living history of the community. An education kit by the museum for third-graders across Canada consists of a large fold out floor map showing roads and community centers. Blocks of houses and other buildings are used by children along with cards in teacher-led exercises that discuss not only the former life of the community, but the ways the issues they confronted persist today. ${ }^{12}$ The museum also stakes the ground throughout the landscape with signs that identify the location of former houses and community facilities like the post office, water well, and store. These mapping practices - both traditional and non-traditional - provide didactic and discursive experiences of the community. It is the goal of this paper to understand how these practices can also be projective tools in the design of space in racialized contexts. In order to understand this we have first applied a "mapping operations" framework to two maps addressing racialized contexts.

\section{MAPPING OPERATIONS IN RACIALIZED LANDSCAPES}

Mapping civic space can make otherwise invisible socio-political relationships visible. By choosing what to show and not show this curation of visibility is an act of both agency and power in racialized contexts. Exercising this power can both reinforce and subvert dominant-insurgent power dynamics in civic space. Corner and others have noted the significant role of "personal authorship and intent," calling to attention notions of bias and political positioning. ${ }^{13}$ With the following two examples we read authorial intention into the curation of visibility and invisibility in these contexts; specifically the former colony and now state of Virginia in the United States. The first example is a typical map from colonial expansion and paints a picture of pastoral dominance. The second, a naïve drawing from the present day erases an African-American presence, constructing a white supremacist vision of a town. 


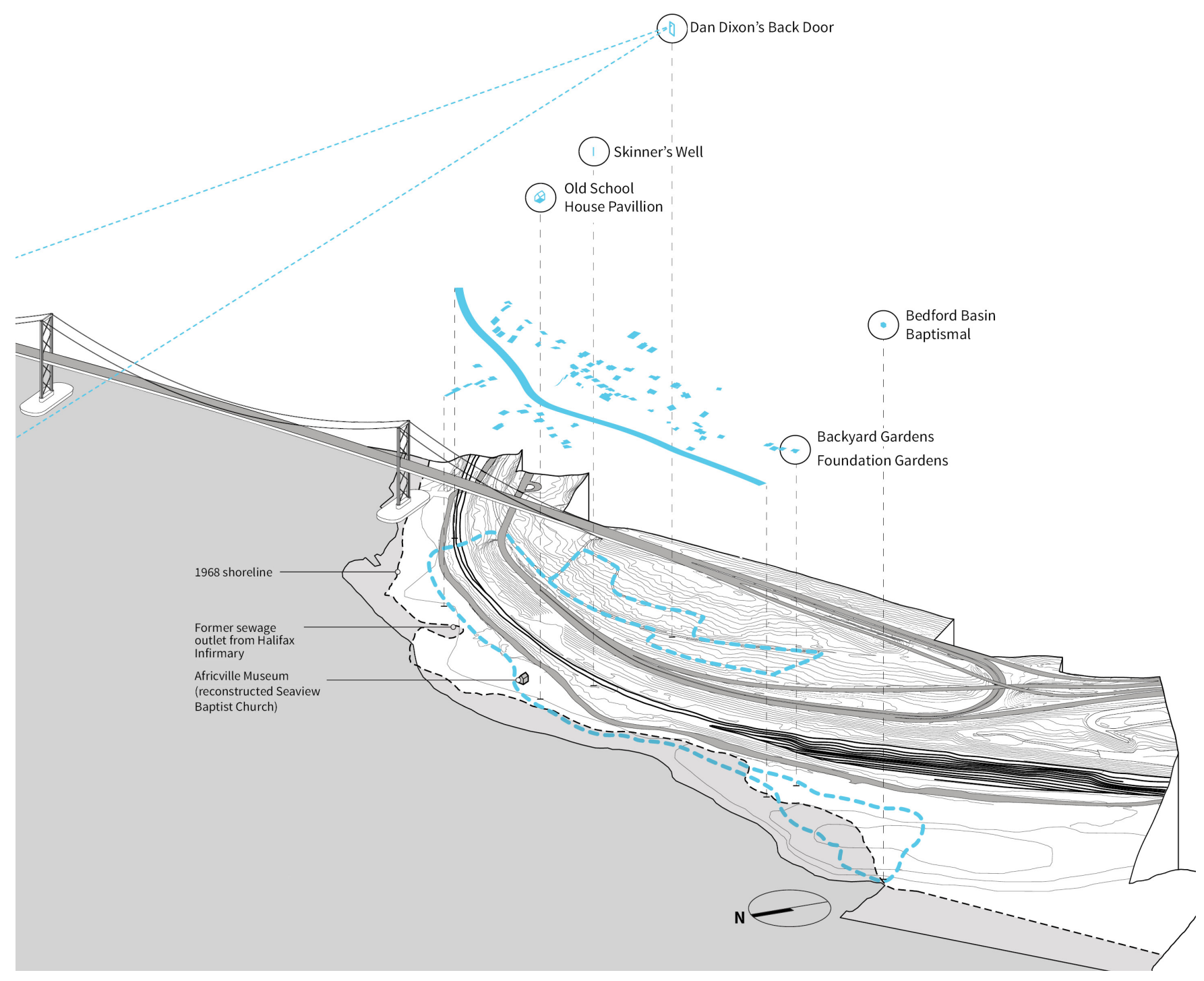

Figure 1: Africville Walk, an interpretive landscape program. James Forren.

are the plottings which charge the ambiguous canvas of fields

Rhizome and Accuracy. William Hole's map of early colonial Virginia, Virginia. Discouered and Discribed by Captayn John Smith 1606 (Figure 2), demonstrates the performance of mapping as a political act and its subsequent racialized implications. John Brian Harley (1988) articulates this typical colonial map's program of constructing an inviting, manicured depiction of a landscape that was, in reality, a wilderness. ${ }^{14}$ This agenda, authored by the British monarchy, assured the viewer of a European conscription and control of the land. Positioning this example in the lexicon of Corner's analysis we can read the field as the blank whiteness of the flattened land mass and the soft gray tone of water, with rivulets of rivers penetrating into the blank earth. Trees, hills, place names are read as extracts: constructed in a tidy, reassuring manner: in the spirit of miniaturized furniture easily traversed by the viewer and evoking the English countryside. And the visual program of text and symbols which accompanies the map and extracts with clear proclamations of state authority and ownership over the land and its inhabitants.

An absence of particular information in the plotting operates within the map as an "instrument of exclusion". ${ }^{15}$ The indigenous presence is silent and, where present, marginal and dissociated from the territory itself. The impression is that of a terrain where the native inhabitants have been removed, existing now as enlarged set-pieces on the margins in the posture of English country gentlemen. The absence of accuracy, not only in depictions of scale, but of cultural realities, works in favor of the monarchy, encouraging further exploration of the territory.

Through the lens of Corner's framework the map performs as a type of rhizome wherein the viewer in enticed to imagine the network of rivulets extending beyond the border and into further groomed unmarked territory. It is a type of generic 


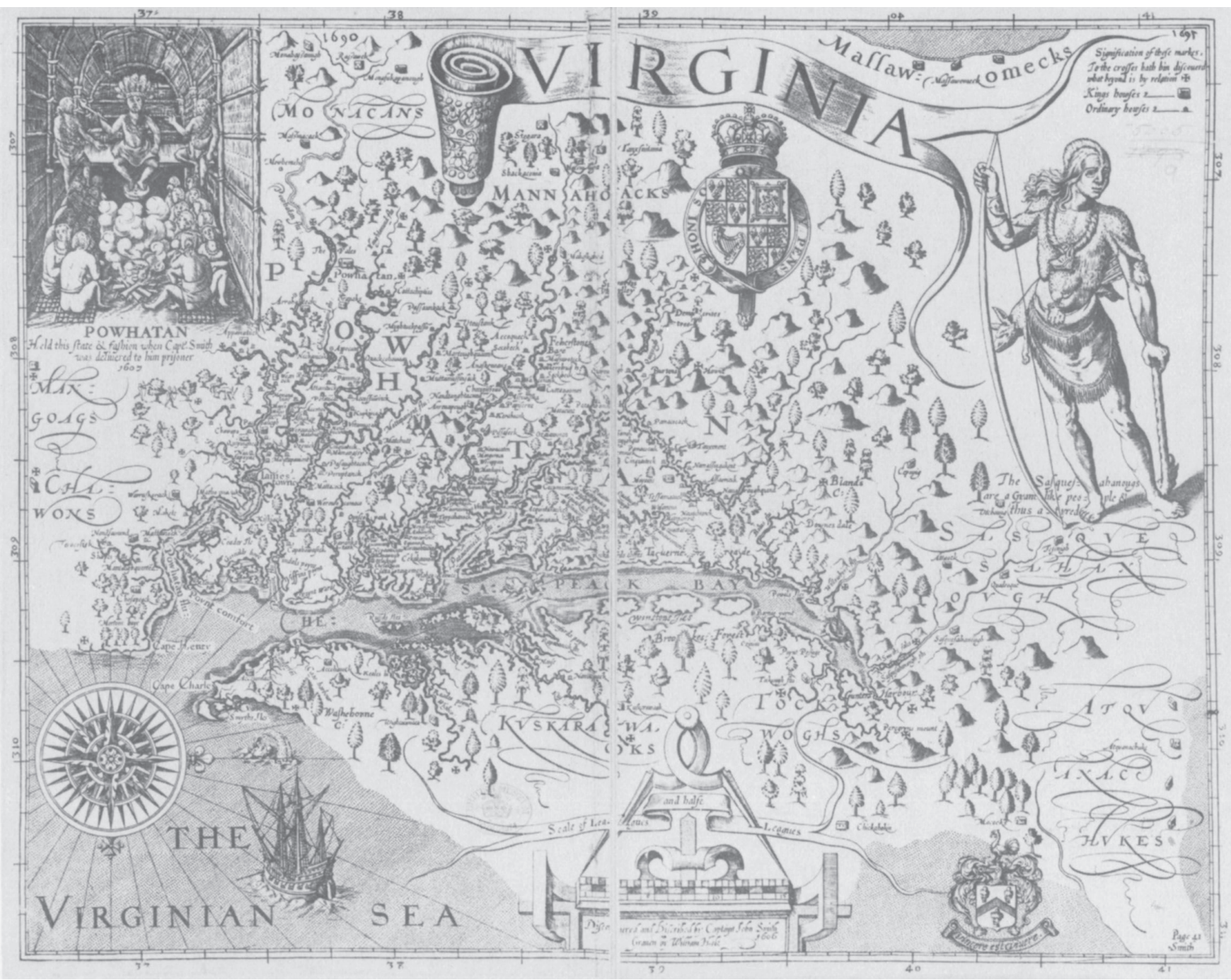

Figure 2: Virginia. Discouered and Discribed by Captayn John Smith 1606, William Hole, 1625. Library of Congress Rare Book and Special Collections Division (Control Number 2001695744).

network made particular by the data of landscape surveys. However, if we contrast this with Corner's discussion of Charles Joseph Minard's 1885 map of Napoleon's campaign one element that distinguishes Minard's is the use of accurate data and adherence to that data in the temporal charting of Napoleon's advance to and retreat from Moscow. The constraint of scale and accuracy lends an objectivity to the construction which would frustrate the willful 'landscaping' of the Captain John Smith map. If this same Virginia landscape were accurately surveyed and depicted, a more precise account of indigenous land and its occupation could make apparent the true vastness and complexity of the region. In this map's use of composition and form the falsification of distance combined with a distorted depiction of data perform as generative acts which prefigure ensuing expeditions to the mid-Atlantic coastline.

Drift and Authorship. This distortion of space to serve an implicit agenda is radically employed in a map (figure 3 ) discussed by Mieka Polanco in her essay, "Not To Scale."16 The map is drawn by an elderly man of European, colonial descent, Ernest Greene (pseudonym) who grew up in a small town, Union, in the state of Virginia. The map depicts Union as remembered by Mr. Greene and consists of a blank field laced with extracts including a network of roads running between and around landmarks and buildings. Annotations, arrows, and circles act as plottings identifying important relationships. The map is reproduced in Polanco's essay blurred, without detail, to protect the personal information of people identified in the map. Polanco notes in her essay that the map as drawn by Mr. Greene uniformly edits out African-American names, landmarks, buildings, and property boundaries. The African-American narrative is excluded not simply by a leaving out or off of place names. Labeled "Not to Scale" by the author the map excludes blackness by abutting Euro-American owned properties against each other, thus "over-writing" the presence of "blackness" in the town. In this act the property boundaries behave as plottings showing 


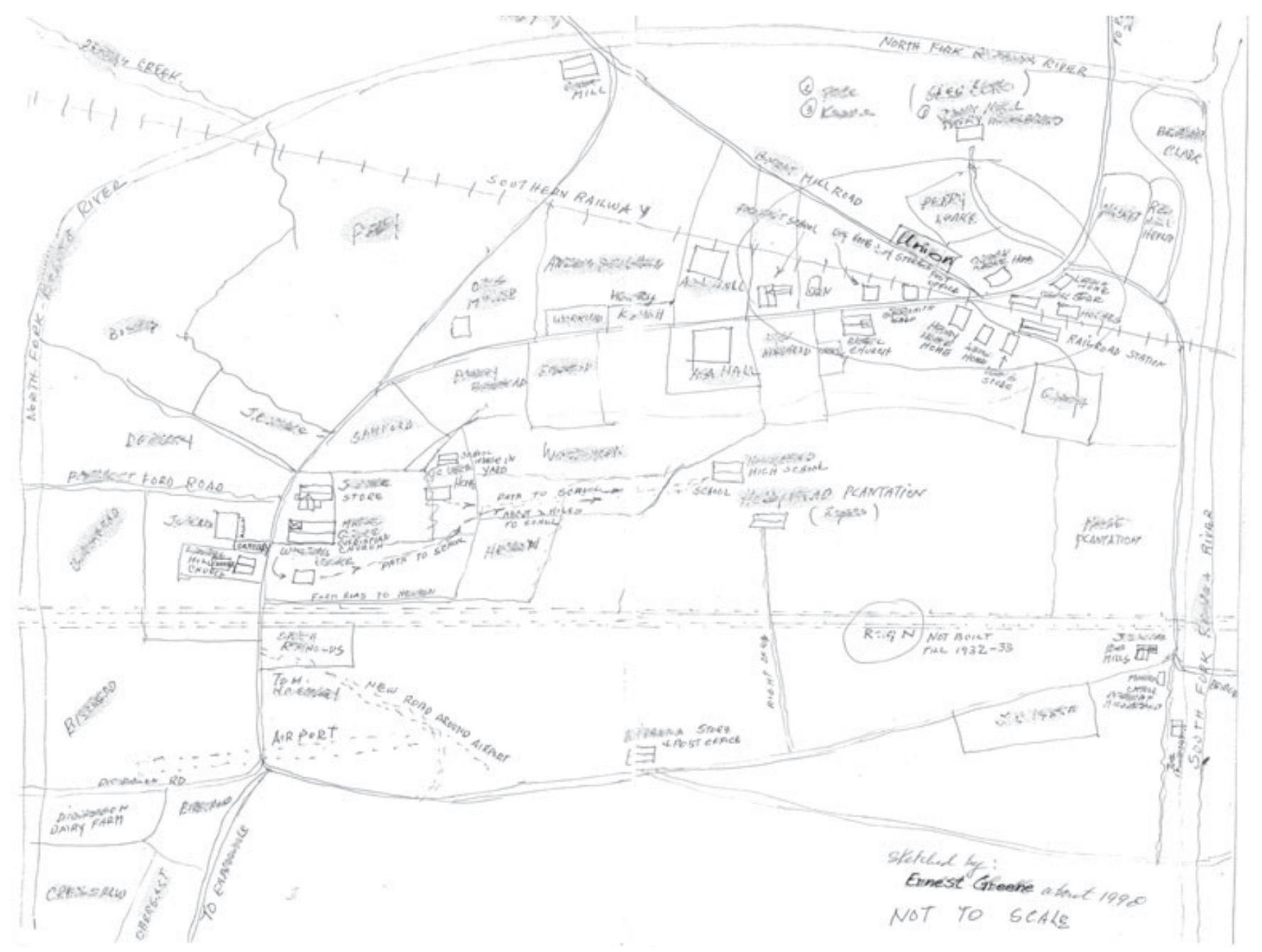

Figure 3: Map of Union, by Ernest Greene (pseudonym). Reproduced by permission of the American Anthropological Association from Transforming Anthropology, Volume 20, Issue 2, pp. 118-130, 2012. Not for sale or further reproduction.

an otherwise invisible mental erasure of black space by a mindset privileging "whiteness."

As the imagined construction of an individual this map can be read through the lens of drift in Corner's taxonomy where spatial expansion and compression is produced by subjective perception. As a subjective document the map is a psychological portrait of its author - a request to see the world through his eyes - as much as it is an account of physical, spatial territory.

"Viewers of Greene's map are asked to move their imagined bodies through imagined space-and, indeed, imagined time-back to Mr. Greene's youth, tracing along the handdrawn roads not a correspondence to the physical landscape, but to a memoryscape, where experiences are embodied in a different 'scale.'"17

Corner identifies that this subjective perception can be leveraged as a resistance to state dominance. Connecting the timing of the map's construction with the event of Union's recognition as a "Historically Black Community" in 1998 Polanco speculates that Mr. Greene was motivated by political will as much as nostalgia. For Mr. Greene, Union was a white town, not black, and his map proves it. This is a miniature act of political agency refuting a state-sponsored story about Union. The reality of Union is much more complex than either storyline and involves sets of inter-mingled "black-white" relationships as attested by Ernest Greene's own discussion of laborers on his family's property. However, Ernest Greene's map demonstrates how acts of visibility around civic heritage - formal, compositional acts - resonate with socio-political agency. Furthermore Polanco points out that Ernest Greene's map, as a tangible artifact, will circulate more readily as a primary source, than an oral history would. ${ }^{18}$

These two examples reveal important relationships between a map's authorship and its techniques of construction. Although misguided, Ernest Greene's map does not assume a guise of objectivity. It is a transparently subjective document. 


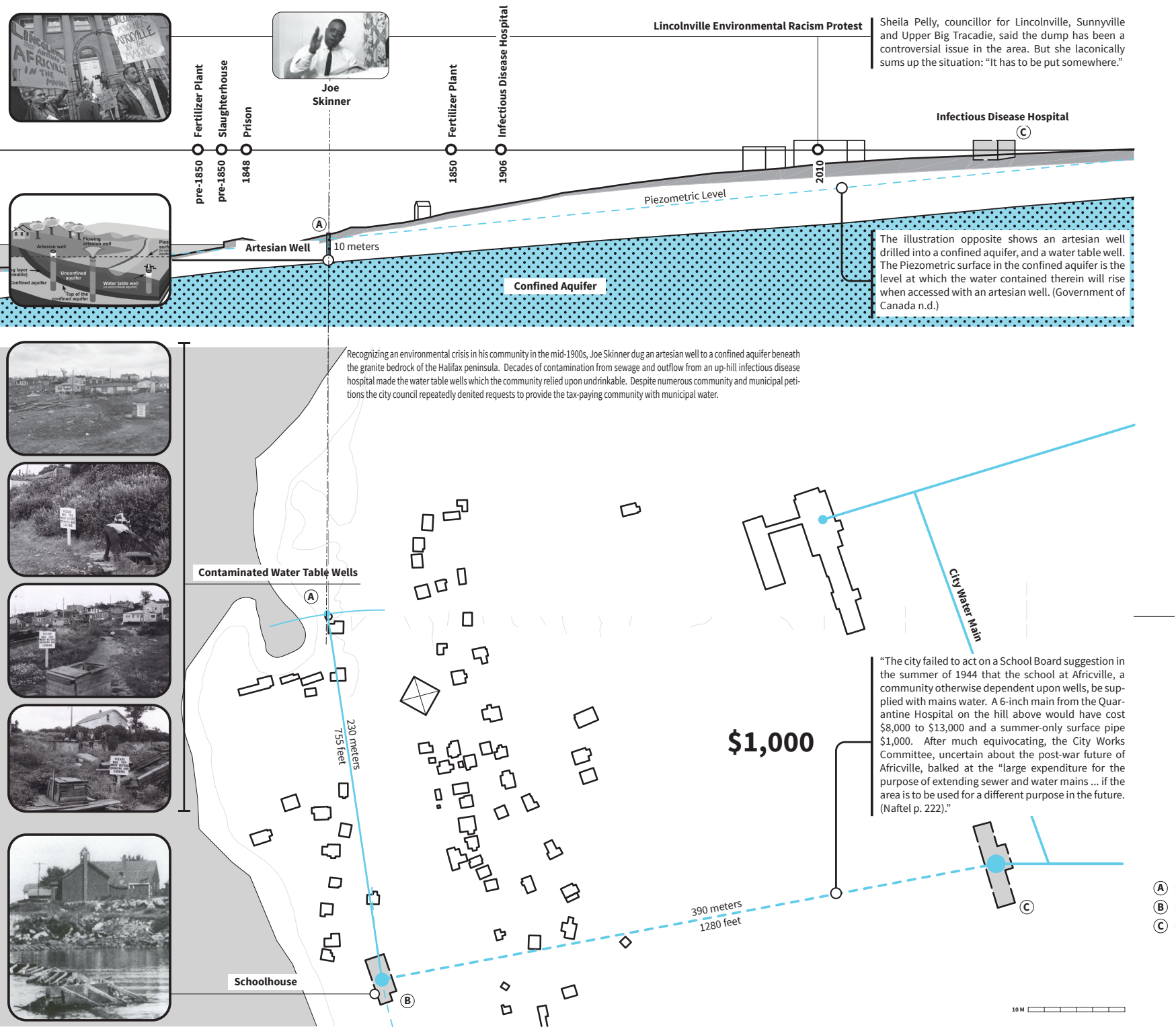

Figure 4: Skinner's Well, by authors

Thus, as a drift operation the map authentically communicates this point of view. As a state-sponsored document, however, the distortions of scale in the Captain John Smith map are counterproductive to an authentic understanding of place. Thus we must reckon with the authorship of a map in selecting a technique. This reckoning includes considerations of scale and accuracy. In addition to understanding the relationship between author and technique, we see here methods for agency in the ability of mapping operations to collapse space and time: to curate data and information in dialogue. On a single page Ernest Greene was able to reference "white" establishments and homes, compressing them in the temporal space of his childhood (1918-1934) in a coherent white history. William Hole was able to place a royal crown over the territory of the "Mannahoacks" as an omnipresent authority. Through reckoning with authorship and engaging spatio-temporal compression the mapping operations undertaken in Africville reimagine possibilities within the practice and projective potentials beyond it.

\section{MAPPING OPERATIONS IN AFRICVILLE}

The projects presented below pilot techniques building on Corner's template of "relational reasoning" where the interplay of formal elements mimics and informs actual interactions among the forces and constituencies they represent. ${ }^{19}$ The present mapping program focuses on a scaled, instrumental engagement of the technology: incorporating oral, written, visual, and experiential knowledge in analytical documents. Through interviews, archival, and field research the researchers have attempted to spatialize and condense textual and oral accounts fragmented across sources. The conclusion of this paper will touch upon how these analytical documents may then become projective in the production of space in the landscape. 


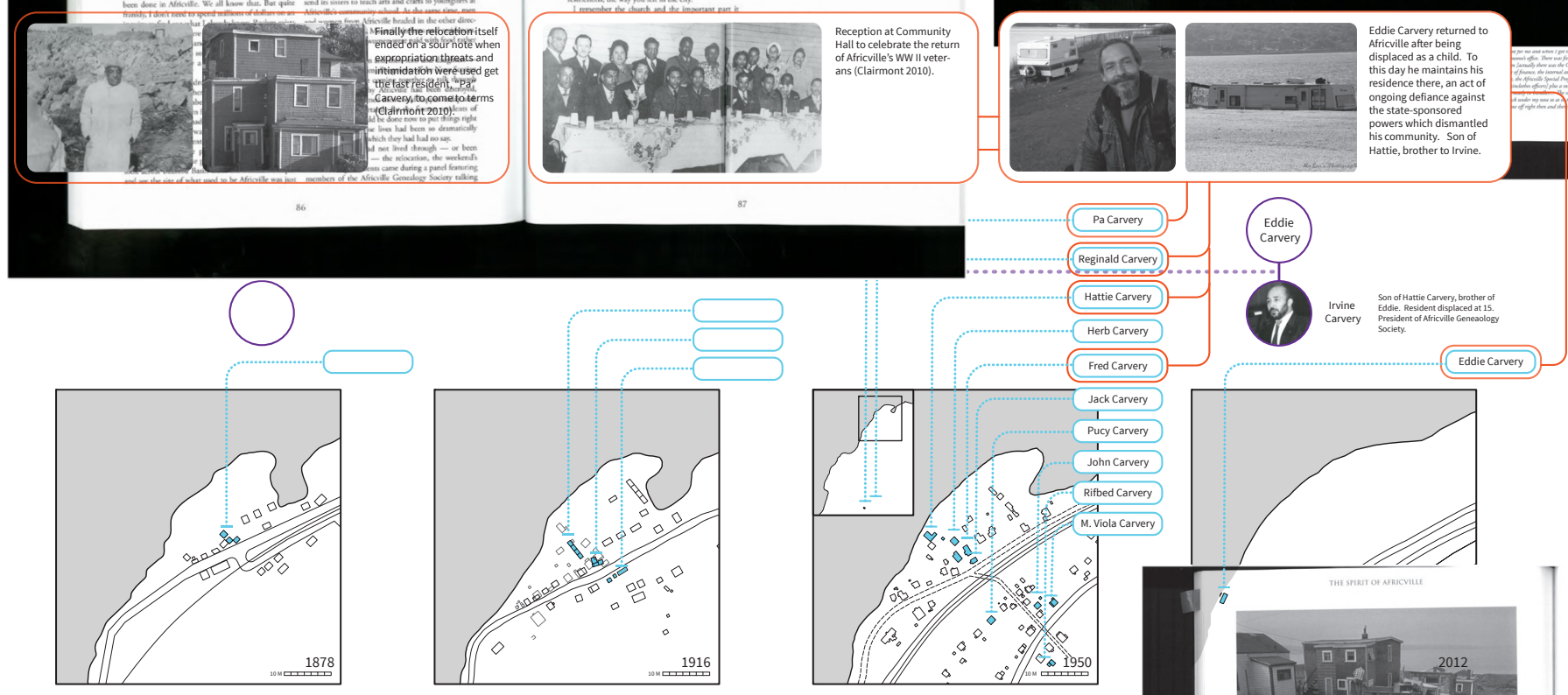

Figure 5: Carvery Map, by authors.

The work adopts a gameboard approach where a neutral field hosts extracts between which plottings explain otherwise invisible relationships: the collected data of interviews, field, and archival research. Because the authors are outside the community these maps host an accurately dimensioned network of narratives. This provides a level of control ensuring the information conveyed is accurate as opposed to the author's construction. In the maps the field is typically a white or grey expanse bordered by thin black lines; the extracts are solid black shapes and figures; and the plottings are images, colored lines and shapes.

Skinner's Well and Environmental Racism. Today Skinner's Well is a story told in texts, conversation, and markers in the landscape. The map here attempts to condense the threads of this story in a multi-layered depiction of an individual's resistance against environmental racism. The City of Halifax repeatedly denied petitions from the community of Africville for a municipal water supply. Even after the urging of the Halifax School Board to supply water for the community school, the city decided it was too dear an investment to extend the waterline 1300 feet, citing the "uncertain future" of the community. ${ }^{20}$ This left residents to supply themselves with water from ground wells that drew from the water table. The problem with this solution was that the ground water was unsuitable for consumption. This was due to the city's location of an Infectious Disease or Quarantine Hospital uphill of the community whose overflow contaminated the ground water. Joe Skinner, a resident of the community, knew there was a contained aquifer below protected from hospital run off. This map (figure 4) tells the story associated with contaminated water in Africville, highlighting the many ground wells as well as the distance required for the City of Halifax to have extended its water line and the distance for the schoolhouse teachers and children to travel for the artesian well. This reterritorializes the landscape as a site of water scarcity: demonstrating both the geographic nearness and socio-political distance of clean water. Through the extract of time this narrative is also connected to contemporary stories of environmental racism still active in Nova Scotia including a recent land fill dispute in the community of Lincolnville: a dispute directly connected by protestors to the story of Africville. As a gameboard map Skinner's Well relies on "local knowledge and direct participation in the field" providing "detailed ... sense of local dynamics and desires" 21 and in this instance it holds social, political, and material conditions which may not otherwise be visible to the eye. By plotting this in the field we are able to reterritorialize the landscape in historic and contemporary stories of environmental racism.

Carvery Map and Informal Relations. The significance of family names and lineage within the community is due in part to the interdependency between extended families where space, food, financial and other resources were pooled and duties were fluidly dispersed. Through maps from the city archives we have found individual names assigned to documented houses. From these documents we can see the extent to which certain family names predominated. A handful of names accounted for the four hundred or more residents of the community. Carvery Map (figure 5) shows the location of houses of the Carvery family over time. Photos of the Carvery family from records place a face as well as recorded accounts of the family members within the territory. The Carvery family has played a significant role in the community over several generations. Pa Carvery was the last resident to be relocated in the early 1970 s. In a younger generation, Eddie Carvery and Irvine Carvery, are important figures in the Africville community today. Irvine is a founder of the AGS and 
has served as its president until only recently. He continues to lead the community during services at the Reunion and has become one of their major public voices. Eddie Carvery sustains a different kind of visibility for the community living on the land in a trailer for over twenty five years. With a sign reading "Africville Protest" Eddie has endured several thefts and burnings of his trailers, including one removal by the city while he was in the hospital. ${ }^{22}$ Carvery Map demonstrates the significance of a geography of home over time as the family group expands and then radically contracts. By highlighting the particular Carvery homes and linking them to identifiable characters in the community and family relationships we see the overlaps in generational and geographic relations and gain insight into the space of the Carvery family both geographically and socially. Blank name placeholders also allow for further knowledge gathering through community research while simultaneously marking gaps in knowledge. These plottings show a network of kinship ties linking the immaterial connection of family to the material of buildings.

\section{PROJECTION AND RETERRITORIALIZATION}

Within the gameboard discussion Corner identifies that these maps "suggest foundations for future work." 23 The mapping operations described here have been pursued as artifacts, didactic displays, and projective instruments for future landscape interventions. Although drawn in part by the hand of a white, male author with the same lineage as Ernest Greene, rather than erase a black presence these maps render African-Nova Scotian space visible in heritage narratives of the city. With this intention the research continues to address questions of privilege and community benefit. Daniel Paul (2006) identifies among authors of European descent in North America, especially males, an inherent blindness to the atrocities wrought on racialized populations by their ancestors as well as to the privilege these atrocities have afforded them. ${ }^{24}$ The author's voice of privilege must do work for its own awareness when speaking about and within racialized contexts. The research addresses this concern through a heterogeneous approach which considers multiple voices and community benefit in doing work the community finds valuable.

The projective capacity of these maps occurs through clearly noted gaps in information and new lines in the landscape. Gaps of information in Carvery Map are noted by empty bubbles. These facilitate dialogue while also enhancing awareness of the landscape. They are devices sparking conversation and discovery: "That is the house of..., it...." These conversations open doors to broader swaths of information. In addition to contributing to a heritage expression of the community of Africville on its own terms, these conversations transform the imaginations of designers working with the community.
New lines and boundaries in the landscape include the cluster of homes in the Carvery Map and the organizational axes in Skinner's Well. These reframe our view of the landscape. The locus of the well location hinges the activity of the map and becomes a more significant node in our vision of the landscape. This changes how we see the land and how we can imagine working within it. This reterritorialization provides a new set of markers - a new geometric scaffolding beyond property boundaries - to work within. As this is not a landscape of a Eurocentric imaginary the charting of these lines are not psychogeographic drifts. Thus, it is important that the mapping program remain within the gameboard: an objective projection open to the interplay of many constituents. To be a truly productive gameboard these depictions must be drawn to scale.

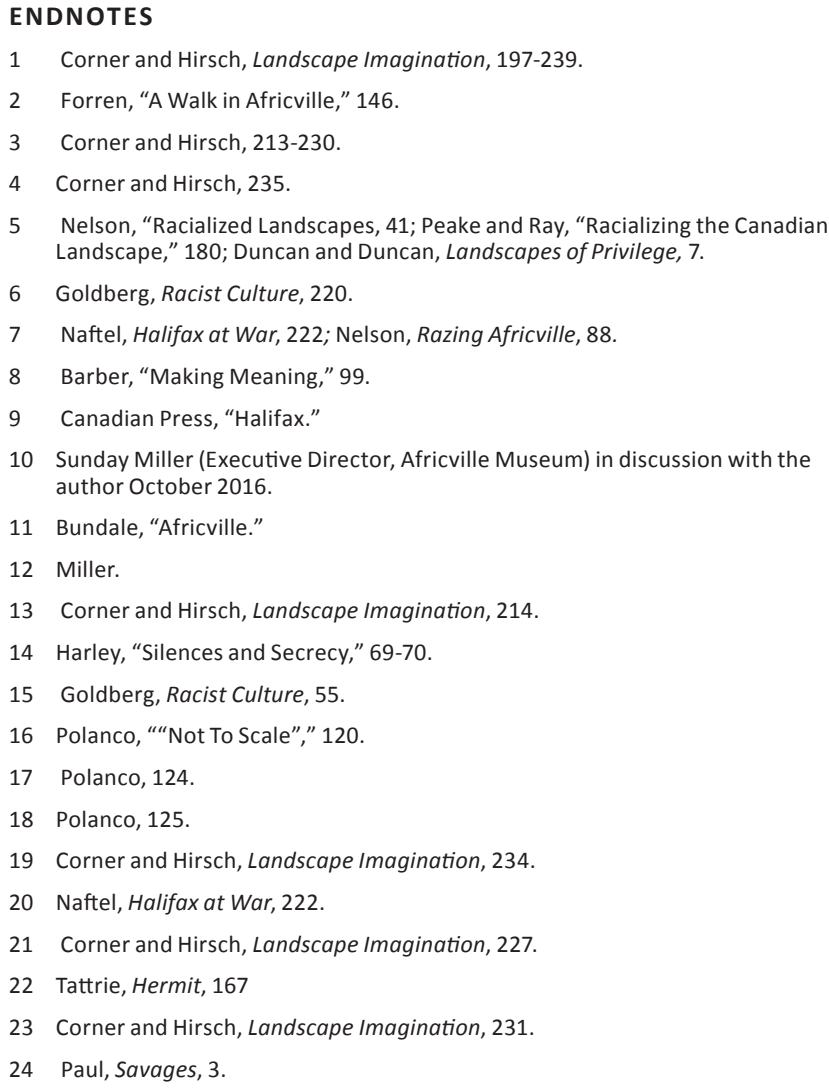

\section{REFERENCES}

Barber, Lachlan B. "Making Meaning of Heritage Landscapes: The Politics of Redevelopment in Halifax, Nova Scotia." Canadian Geographer / Le Géographe Canadien 57, no. 1 (2013): 90-112.

Bundale, Brett. "Africville Land Settlements Possible." The Chronicle-Herald (Halifax, NS), Dec. 16, 2014. Retrieved from http://thechronicleherald.ca/ metro/1258163-africville-land-settlements-possible

Canadian Press. "Africville Timeline." Accessed January 10, 2018. http://cponline. thecanadianpress.com/graphics/2014/africville/index.html.

Canadian Press. "Halifax Apologizes for Razing Africville." CBC News, Feb. 24, 2010. Retrieved from http://www.cbc.ca/news/canada/nova-scotia/ halifax-apologizes-for-razing-africville-1.894944 
The Chronicle Herald. "Environmental racism focus of project." Accessed January 10, 2018. http://thechronicleherald.ca/ novascotia/1158234-environmental-racism-focus-of-project

The Chronicle Herald. "Herald Lifestyles: Turning Points: The Razing of Africville an epic failure in urban community renewal." Accessed January 10, 2018. http:// thechronicleherald.ca/thenovascotian/1521817-turning-points-the-razing-ofafricville-an-epic-failure-in-urban-community-re

Clairmont, Donald H. J., Magill, Dennis William, and Nova Scotia. Department of Public Welfare. Africville Relocation Report. Dalhousie University. Institute of Public Affairs. I.P.A. ; No. 102. Halifax: Institute of Public Affairs, Dalhousie University, 1971.

Clairmont, Donald H. J., Magill, Dennis W., and Canadian Electronic Library. Africville: The Life and Death of a Canadian Black Community. 3rd ed. Canadian Electronic Library. Books Collection. Toronto: Canadian Scholars' Press, 1999.

Clairmont, Donald H. J., and Africville Genealogy Society. The Spirit of Africville. 2nd ed. Halifax, N.S.: Formac Pub., 2010.

Corner, James, and Hirsch, Alison Bick. The Landscape Imagination: Collected Essays of James Corner, 1990-2010. First ed. New York: Princeton Architectural Press, 2014.

Cosgrove, Denis E. Mappings. Critical Views. London: Reaktion, 1999.

Duncan, James S., and Duncan, Nancy. Landscapes of Privilege: The Politics of the Aesthetic in an American Suburb. New York: Routledge, 2004.

Forren, James. "A Walk in Africville: Visibility Strategies in Contested Heritage Landscapes." In Brooklyn Says, "Move to Detroit": 105th ACSA Annual Meeting, Detroit, MI Project Proceedings. Luis Francisco Rico-Gutierrez and Martha Thorne, ed. New York: ACSA Press, 2017, 146-147.

Goldberg, David Theo. Racist Culture: Philosophy and the Politics of Meaning. Cambridge, Mass.: Blackwell, 1993.

Government of Canada. "Water sources: groundwater." Accessed January 10, 2018. https://www.canada.ca/en/environment-climate-change/services/water-overview/sources/groundwater.html.

Halifax Regional Municipality. "Municipal Archives: Remembering Africville: Source Guide." Accessed January 10, 2018. https://www.halifax.ca/about-halifax/ municipal-archives/source-guides/africville-sources.

Harley, J. B. "Silences and Secrecy: The Hidden Agenda of Cartography in Early Modern Europe." Imago Mundi 40 (1988): 57-76.

Jackson, Peter. "Constructions of 'Whiteness' in the Geographical Imagination." Area 30, no. 2 (1998): 99-106

McKittrick, Katherine, and Woods, Clyde Adrian. Black Geographies and the Politics of Place. Toronto, Ont.: Cambridge, Mass.: Between the Lines; South End Press, 2007.

Naftel, William. Halifax at War: Searchlights, Squadrons and Submarines, 19391945. Halifax, N.S.: Formac Pub., 2008.

Nelson, Jennifer J., and Scholars Portal. Razing Africville a Geography of Racism. Toronto [Ont.]: University of Toronto Press, 2009.

Nelson, Lise. "Racialized Landscapes: Whiteness and the Struggle over Farmworker Housing in Woodburn, Oregon." Cultural Geographies 15, no. 1 (2008): 41-62.

OpenFile Halifax. "OpenFile Halifax.” Accessed January 10, 2018. http://openfilehfx.tumblr.com/

Peake, Linda, and Brian Ray. "Racializing the Canadian Landscape: Whiteness, Uneven Geographies and Social Justice1." Canadian Geographer / Le Géographe Canadien 45, no. 1 (2001): 180-86.

Paul, Daniel N. We Were Not the Savages: Collision between European and Native American Civilizations. Third ed. First Nations History. Halifax, Nova Scotia: Fernwood Publishing, 2006.
Polanco, Mieka B. "“Not To Scale”: Mapping Race in a Virginia Historically Black Community." Transforming Anthropology 20, no. 2 (2012): 118-30.1

Sandercock, Leonie. Making the Invisible Visible: A Multicultural Planning History. California Studies in Critical Human Geography; 2. Berkeley: University of California Press, 1998

Tattrie, Jon. The Hermit of Africville : The Life of Eddie Carvery. East Lawrencetown, N.S.: Pottersfield Press, 2010

Thomson, Aly. "Halifax's Africville Museum: A Reflection of an Oppressed Community." The Canadian Press (Toronto), July 01, 2013.

Toronto City News. "Timeline of Africuille's history in Halifax." Accessed January 10, 2018. http://toronto.citynews.ca/2016/11/30/ timeline-of-africvilles-history-in-halifax/.

Waterton, Emma, and Watson, Steve. Culture, Heritage and Representation Perspectives on Visuality and the past. Heritage, Culture, and Identity. Farnham, England; Burlington, VT: Ashgate, 2010.

Wood, Denis, and Fels, John. The Power of Maps. Mappings. London: Routledge, 1993.

Image Credits, Skinner's Well (from bottom): Image Credits: 1. Author Unknown (Clairmont 2010, p 19); 2. Nova Scotia Archives/Bob Brooks (Canadian Press 2018); 3. Author Unknown (Clairmont 2010, p 58-59); 4. Nova Scotia Archives/Bob Brooks (Chronicle Herald "Turning" 2018); 5. Halifax Regional Municipality Archives (HMA 102-16N-0065.H); 6. Author Unknown (Government of Canada 2018); 7. Halifax Chronicle (Tim Krochak/Staff/File) (Chronicle Herald "Environmental" 2018); 8. Photographs Collection, Nova Scotia Archives (Clairmont 2010, p 77).

Image Credits, Carvery Map (from left): 1. Halifax Chronicle Herald Archives (Clairmont 2010, p 75); 2. Unknown (Clairmont 2010, p 21); 3. Photo by Clara Adams (Clairmont 2010, p 46-47); 4. The Canadian Press/Andrew Vaughan (Toronto City News 2018); 5. Author Unknown (OpenFile Halifax 2018); 6. Photo by Donna James (Clairmont 2010, p 87) 